Relations industrielles

Industrial Relations

\title{
"Le monde du travail ", Travail-Québec, vol. 14, no 4, septembre 1978, 48 pp.
}

\section{Gérard Dion}

Volume 33, numéro 4, 1978

URI : https://id.erudit.org/iderudit/028921ar

DOI : https://doi.org/10.7202/028921ar

Aller au sommaire du numéro

Éditeur(s)

Département des relations industrielles de l'Université Laval

ISSN

0034-379X (imprimé)

1703-8138 (numérique)

Découvrir la revue

Citer ce compte rendu

Dion, G. (1978). Compte rendu de [« Le monde du travail », Travail-Québec, vol. 14, no 4, septembre 1978, 48 pp.] Relations industrielles / Industrial Relations,

33(4), 711-711. https://doi.org/10.7202/028921ar

Tous droits réservés @ C Département des relations industrielles de l'Université Laval, 1978
Ce document est protégé par la loi sur le droit d'auteur. L'utilisation des services d'Érudit (y compris la reproduction) est assujettie à sa politique d'utilisation que vous pouvez consulter en ligne.

https://apropos.erudit.org/fr/usagers/politique-dutilisation/ 
«Le monde du travail», Travail-Québec, vol. 14 , no. 4 , septembre 1978,48 pp.

La revue Travail-Québec a eu la bonne idée de présenter ce numéro thématique consacré aux organismes québécois qui œuvrent dans le monde du travail. Sans prendre la responsabilité du contenu des articles, Travail-Québec a demandé à chaque groupement de faire son autoportrait.

On comprend que c'est avec précaution et une certaine réserve qu'il faut lire ces exposés sur la nature, l'organisation, les orientations et les effectifs des groupements. Toutefois, l'essentiel s'y rencontre et cette information est intéressante et utile.

Voici la liste des groupements: Centrale de l'Enseignement du Québec, Centrale des Syndicats nationaux, Centrale des Syndicats démocratiques, Fédération des Travailleurs du Québec, Congrès du Travail du Canada, Conseil du Patronat du Québec, Chambre de Commerce de la province de Québec, Conseil des Hommes d'affaires québécois, Centre des Dirigeants d'entreprise, Association des Manufacturiers canadiens.

Ce numéro comporte des lacunes inexplicables tant du côté des groupements des travailleurs que de celui des employeurs. Sans vouloir être exhaustif, mentionnons en quelques unes.

On sait, par exemple, qu'au Québec le nombre et les effectifs des syndicats indépendants de ce que l'on continue d'appeler les grandes centrales, et qu'il ne faut pas confondre avec les syndicats de boutique, sont très importants. Cette constatation a été souligné dans Aspects de la réalité syndicale québécoise 1976 de François Delorme et Gaspar Lassonde. Certains de ces groupements ont une influence prépondérante dans certains secteurs et jouent un rôle plus considérable avec les centrales. Ils auraient mérité d'être présentés dans ce numéro. Ainsi, le Syndicat des Fonctionnaires provinciaux du Québec, la Fédération des Employés municipaux et scolaires du Québec, la Fédération des Syndicats professionnels d'infirmières et d'infirmiers du Québec, la Provincial Association of Protestant Teachers, la Provincial Association of Catholic Teachers, les Infirmières et infirmiers unis (United Nurses) etc., etc.
Du côté patronal, on s'étonne d'y voir figurer le Conseil des Hommes d'affaires québécois fondé en 1973 qui est un groupement à caractère politique n'œuvrant pas dans le monde du travail alors qu'on note l'absence d'associations extrêmement représentatives qui négocient des conventions collectives comme la Fédération des Commissions scolaires catholiques du Québec, l'Association des hôpitaux de la province du Québec, l'Association des Entrepreneurs en construction du Québec etc.

Pour établir ce que c'est qu'un groupement patronal, la direction de la revue aurait eu avantage à consulter un article que nous avons publié il y a déjà vingtcinq ans dans la revue Relations industrielles, (vol. 8, no. 4) «Les groupements patronaux - essai de classification». Malgré les ajustements nécessaires en raison de l'évolution normale des institutions dans un domaine aussi dynamique, ils auraient trouvé des lignes de démarcation qui restent toujours valables.

Les lacunes que nous venons de signaler sont regrettables. Elles nous empêchent d'avoir une vue plus complète des associations dans le monde du travail au Québec. Elles sont assez considérables qu'elles pourraient être corrigées en consacrant un autre numéro thématique de la revue sur le même sujet.

\section{Université Laval}

Gérard DION

\section{Collective Agreement Arbitration in Canada,} by Earl Edward Palmer, Scarborough, Butterworths, 1978, 723 pp.

Cet ouvrage du professeur Palmer constitue un véritable traité que les spécialistes en la matière s'arracheront sans nul doute. Tel que le mentionne humoristiquement l'auteur, «Brown and Beatty may be a Rubens, but there is still room (and follow ers) for a Van Gogh». On pourra trouver dans ce volume un essai sur l'arbitrage en tant que système (partie I), puis un exposé sur les règles suivies par les arbitres lors du contrôle de l'application de la convention collective pour trois grandes catégories de 